\title{
MALPRACTICE REFORM THROUGH CONSUMER CHOICE AND CONSUMER EDUCATION: ARE NEW CONCEPTS MARKETABLE?
}

\author{
MAX W. FINE* \\ and Jonathan H. Sunshine ${ }^{\dagger}$
}

\section{INTRODUCTION}

Will consumers voluntarily accept changes in the ways cases of medical malpractice are handled? Yes, under certain circumstances, they maybecause the conditions are right.

Consumers in this context include not merely individuals but also employers and unions who make volume purchasing decisions and are responsible for individuals' health insurance bills. Until very recently, nearly all these large-scale purchasers of health benefits accepted massive medical cost increases with hardly a wince. Indeed, they continued to expand coverage. Despite rhetoric to the contrary, their behavior suggested that they felt virtually no pain from soaring malpractice costs-or other cost increases. "Defensive medicine" was something doctors did to children, with needles, not a malpractice-law-induced cost problem. ${ }^{1}$

In the last few years, however, the scene has changed dramatically. Today, hardly a CEO of a Fortune 500 company or a trustee of a union health and welfare plan is unconcerned about health benefit costs. Some companies seek solace in group commiseration at business coalition meetings. ${ }^{2}$ Others have shifted the burden to employees through larger deductibles and co-payments. Union leaders, harkening to a rising chorus of demands from the rank-and-file for MOB (maintenance of benefits), have resisted the increased deductibles and co-payments whenever possible. But they have accepted certain other limitations on health care services covered by their negotiated plans. Predetermination of coverage for inpatient stays, mandatory second surgical

Copyright $(1) 1986$ by Law and Contemporary Problems

* President, Max Fine Associates; Executive Director, American Association of Preferred Provider Organizations; formerly, Executive Director of the Consumer and Labor-supported Committee for National Health Insurance.

$\dagger$ President, Sunshine and Associates; formerly, Economist, U.S. Office of Management and Budget and Veterans Administration Health Scholar.

1. See infra note 6 and accompanying text.

2. See, for example, Coalition Report and other publications from the Clearinghouse on Business Coalitions for Health Action, Washington, D.C. 
opinions, and alternative delivery systems such as PPO's ${ }^{3}$ all impose limitations that would have been rejected by the pace-setting unions only a few years ago. These are the same unions that historically established the benefit patterns followed not only by other unionized industries but also by most other private health benefit plans. Large groups buying health care collectively are more receptive to fundamental changes of all kinds than they have ever been before. Some malpractice reforms may therefore be acceptable to key decisionmakers on the demand side of the market.

Why, after years of negotiating more and more health insurance coverage almost without regard to costs, are unions now willing to accept significant limitations on their members' benefits? And why do plan members accept changes in plans that had been held inviolable for years? The simple answer to these questions is that cost growth has overcome complacency. Health benefit costs have risen so high that both management and labor negotiators face huge political problems among their respective constituencies if they fail to control medical spending. Today, any money wasted on excessive health insurance premiums may be the difference between a company's losing or winning a vital, job-preserving contract. It may be the difference between a labor settlement and a strike. The new awareness of this problem is especially strong among heavy manufacturers and their suppliers, traditionally among the best insured firms and now more than ever feeling heavy competition at home and from abroad.

Individual consumers have accepted the changing features in their health benefit plans, and educational programs have led many to regard some limitations-such as second opinions and efforts concentrating specialized surgery in high-volume centers-as quality enhancements. The medical malpractice problem, precisely because of its adverse impact on costs, is another candidate for private sector initiatives similar to those that are now constraining wasteful practices elsewhere in the health care field. But the private solution must begin with education of consumers, both individuals and groups. Without education, acceptance of the needed changes, desirable as they may be, will be difficult if not impossible to achieve.

3. The literature on cost containment methods such as these is legion, certainly among consumer-oriented benefits publications. See, for example, any issue of Employee Benefit Plan Review. Reliable, published analyses of their effectiveness are rare, but that is another matter; the marketplace already has determined their usefulness. "Predetermination" sets various limits on hospital stays by diagnosis, condition, or procedure. "Mandatory" second opinions not only pay for but require that a patient seek a second medical judgment of the necessity for certain operationssometimes as a condition of paying for the surgery, at least in full. PPO, for "Preferred Provider Organization," is one of the newest acronyms in the field of benefits. PPO's vary enormously ("when you've seen one PPO, you've seen one PPO," it is said), but they routinely feature a somewhat restricted list of providers that patients can see and still get a full level of payment for benefits. Because those providers are economical, accept utilization management mechanisms, and/or offer price discounts, the plan can afford a higher level of coverage of benefits while still generating savings. Non-listed providers' services are still covered, but less favorably for the patient-with a higher cost-sharing burden on the patient, for example. See also text at note 15 infra. 


\section{II}

\section{The Conventional Wisdom and Its Three Errors}

The belief that malpractice and its insurance pose major problems for society seems to rest on two central theses: first, that the over-large and rapidly rising amounts spent on liability insurance for malpractice-about $\$ 2$ billion in premiums for $1983^{4}$-themselves constitute the problem and, second, that reform of the tort-law system as it applies to medical malpractice will bring a solution. ${ }^{5}$ Certainly, most of the outcry about a malpractice "crisis" has been prompted by large insurance premium increases imposed upon physicians, who have descended on their state capitals demanding legal reform. But the conventional view of the problem and its solution is wrong on three counts.

First, malpractice premium prices are not high enough for consumers, as opposed to physicians, to get excited about them. Total health care spending today approaches $\$ 400$ billion a year, not far from two thousand dollars per capita. Two billion dollars-even if doubled to reflect the implicit cost of selfinsurance-amounts to approximately one percent of the total health care costs, "small change" compared to other cost problems that demand attention. Further, it is less than clear that major efforts to solve the malpractice problem will be reflected in significant reductions in malpractice premiums.

A bigger cost concern for consumers is the cost of defensive medicine. This term describes the dominance of legal over medical considerationsextra tests and other procedures that are done to protect a provider against a lawsuit rather than to benefit a patient. ${ }^{6}$ Malpractice-prompted care has been estimated to cost at least $\$ 15$ billion and perhaps as much as $\$ 40$ billion. $^{7}$ That amount represents waste in the medical care system and, as such, is of genuine concern to consumers.

For health care providers, however, defensive medicine has certain attractions entirely unrelated to malpractice. Every dollar of its cost to consumers is an extra dollar in the pocket of some provider-some hospital, physician, or laboratory. Thus, the economic gain from providing extra

4. Best's Ins. Management Reports, On-Line Report, Release No. 18, General Liability and Medical Malpractice Insurance Marketing-1984, at 2 (1985).

5. See, e.g., Special Task Force on Prof. Liab. and Ins., Am. Medical Ass'n, Professional Liability in THE ' 80 s, REPORT 3, at 9 (1985) (originally published as a supplement to AM. MED. News, Mar. 1985).

6. For the classic definition of excessive defensive practices, see U.S. Dep't of HEalth, Educ., \& Welfare, Medical Malpractice: Report of the Secretary's Commission on Medical MalPRACTICE \& APPEndix 14 (1973) (borrowing from Bernzweig, Defensive Medicine, in id. at app. 38).

7. See Special Task Force on Prof. Liab. and Ins., Am. Medical Ass'n, Professional LiABILITY IN THE '80s, REPORT 1, at 16 (1984) (originally published as a supplement to AM. MED. News, Oct. 1984) (reporting the $\$ 15$ billion figure from an earlier calculation by the AMA); Brinkley, A.M.A. Study Finds Big Rise in Claims for Malpractice, N.Y. Times, Jan. 17, 1985, at A1, col. 6 (AMA internal study estimates $\$ 15$ to $\$ 40$ billion in defensive tests and treatments). For an expanded discussion, see also Zuckerman, Koller \& Bovbjerg, Information on Malpractice: $A$ Review of Empirical Research on Major Policy Issues, Law \& Contemp. Probs., Spring 1986, at 85, 107-09. 
services bolsters the legal incentive to practice defensively. Hospital occupancy rates have dropped to 65 percent nationally and continue to fall precipitously. ${ }^{8}$ The number of Americans per physician has fallen from 670 in 1970 to 500 in $1980^{9}$ and is expected to drop to 410 in $1990 .^{10}$ Given fewer patients per provider, providers have ever stronger incentives to find more and more to do for each patient. Defensive medical practice is therefore very much in their economic interest, and it would be a mistake to expect it to end automatically, or even diminish much, if the malpractice crisis were solved.

The conventional wisdom's second error about malpractice is to focus upon the wrong aspect of the $\$ 2$ to $\$ 4$ billion total cost of premiums and selfinsurance. The problem here, from a consumer's standpoint, is not the absolute size of this health care cost, which is only approximately one percent of total health spending. Rather, the problem is that so little of the total goes as benefits to those who are injured by malpractice. Estimates are that only one-third to one-fifth of the premiums paid actually wind up as payments to people who are injured."1 The remaining two-thirds to four-fifths of premiums go to pay lawyers on both sides and to cover administrative costs. This low payback to the consumers who ultimately fund the system is a genuine shame, suggesting that the system is run for the benefit of someone other than consumers.

Equally shameful is the several-year wait that is common before a malpractice case is resolved, even out of court. ${ }^{12}$ A long delay may be convenient for insurers-who can invest 50 cents today and sometimes have available $\$ 1$ or more to pay back at settlement time. ${ }^{13}$ But delay can be catastrophic for any severely injured person who is not financially well-heeled. Indeed, persons who badly need the money because of their injury (or otherwise) must settle quickly - and are therefore most likely to settle for an inadequate amount, since their bargaining power is reduced by their inability to hold out.

The third error is to think that new legislation holds the answer. Practical experience offers little in the way of hope. Many states enacted legal reforms in the malpractice crisis of the mid-1970's. Yet here we are in the mid-1980's

8. American Hospital Ass'n, Trends No. 83, December 1984, Table 2.

9. Nat'l Center for Health Statistics, U.S. Dep't of Health and Human Services, Pub. No. (PHS) 84-1232, Health: United States, 1983, at 161 (1983).

10. Bureau of Health Professions, U.S. Dep't of Health and Human Services, Pub. No. hrS-P-OD-84-4, Report to Congress on the Status of Health Professions Personnel in the U.S. (1984).

11. Special Task Force on Prof, Liab. and Ins., Am. Medical Ass'n, Professional Liability IN THE '80s, RePORt 2, at 13 (1984) (originally published as a supplement to AM. MED. News, Nov. 1984) (estimate of 20 to $25 \%$ return by $\mathrm{D}$. Phillips) (hereinafter cited as AMA TASK Force, Report 2].

12. Nat'l Ass'n Ins. Comm'rs, Malpractice Claims: Final Compilation 21 (M. Sowka ed. 1980) (reporting an average delay of almost four years from incident to settlement in 1978, with the time lag trend increasing). The time from claim to award may be considerably less.

13. However, with settlement amounts rapidly rising for many claims, the purely financial incentive for insurers is to settle rapidly, in types of cases for which award amounts increase more rapidly than amounts set aside as investments can grow. 
with the same problems still, but at a higher level of spending. Perhaps stronger legal medicine could work, but the political reality is that the tort law bar is an extremely strong lobby and has a powerful interest in preserving as much as possible of today's system. As well, surveys indicate that the general public does not support extensive legislative reform. ${ }^{14} \mathrm{~A}$ fight for reform legislation thus does not offer a productive avenue for change. The battle will be bruising, and, cven if some victories are won, they are not likely to cure the problem.

What, then, can be done? From the consumer's standpoint-which represents the broad public interest as well-the three errors noted point to the three key components of the solution: (1) Eliminate the true waste of resources involved in medical care, much of which is represented by defensive medicine; (2) put much more of the premium dollar into injured persons' pockets-and do so much sooner; and (3) do not look particularly to legislation for reform. Consumers and the public will be best served by looking instead to "alternative delivery systems" and their capacity to pursue efficiency in the provision of medical care.

\section{III}

\section{Alternative Delivery Systems}

Alternative delivery systems, including health maintenance organizations (HMO's) and preferred provider organizations (PPO's), are the best vehicles for addressing malpractice problems. Most basically, an alternative delivery system is a set of arrangements in which patients have a financial incentive to use a limited group of providers. In turn, consumers and those who pay for their care gain from the efficiencies effected by selecting economical, highquality providers for membership in the limited group. ${ }^{15}$

Consider one simple example: In most communities, one or more relatively high-cost hospitals charge approximately double what low-cost hospitals charge for the same standard procedures. With conventional insurance, all hospitals' services are covered equally and patients pay nothing, so that they and their doctors continue to use high-cost hospitals in undiminished numbers. Thus, while obvious and large savings can be obtained at some institutions, payers cannot benefit from them, nor need the high-cost providers economize. An alternative delivery system that steers patients to economical, efficient hospitals, however, can markedly lower hospitalization costs and, equally important, can pass those savings on to those it serves. It does not have to underwrite the high costs incurred by

14. McCoy, Public Is of Two Minds About Limiting Plaintiffs Right to Get Rich in Court, Wall St. J., May 20,1986 , at 18, col. 1. The surveys cited are far from ideal in their sampling. They often do not involve systematic sampling of a geographically dispersed population. Nonetheless, the flavor they convey is quite similar. The general public apparently does not support most commonly-proposed legal reforms, except for limitations on attorneys' fees.

15. An alternative system may mandate that its patients use its limited list of providers under normal circumstances, as HMO's typically do, or merely reward those who choose to do so, as do most PPO's. 
patients, providers, insurers, and purchasers who do not care how much health care costs.

To the consumer, the overriding problem with health care in the United States today is that it costs far too much, and its costs are rising with frightening speed. ${ }^{16}$ Alternative delivery systems offer consumers not only lower-priced providers (as in the example) but also the savings that result from an economical style of practice, one that uses less hospitalization and avoids the excessive utilization associated with defensive medicine.

Alternative delivery systems also offer five potential advantages for dealing with various sources of the malpractice problem in the medical system. As later discussion will suggest, they also may facilitate building "better mousetraps" for handling the legal side of the problem and for introducing even more extensive reforms of the malpractice liability system. Before addressing the latter possibilities, consider the five ways in which alternative delivery systems can ameliorate the problem of medical injuries and the high costs associated with medical malpractice.

Alternative delivery systems' first and perhaps greatest contribution is to give providers a reason to abandon defensive medicine and its large-scale wasteful spending. In an alternative delivery system, increasing the number of services to each patient is no longer one of providers' primary routes for increasing net income-quite unlike conventional, insured fee-for-service practice. Rather, in well-run alternative delivery systems, such behavior becomes economically detrimental for providers. Unlike conventional insurance, alternative delivery systems are able to "capture" the savings that result from a more economical style of practice. ${ }^{17}$ These savings can then be shared by patients, payers, and providers alike.

Even if their malpractice insurance premiums increase, practitioners can easily reap gains by giving up defensive medicine inside an alternative delivery system. The reason is that defensive medicine is estimated to cost at least seven times as much as malpractice insurance (and perhaps as much as twenty times as much). Thus, insurance premiums could, for example, double as a consequence of eliminating defensive medicine and of paying claims that might otherwise have been successfully defended, yet the savings would still be much greater than the increased premium costs. (Under the hypothesis that defensive medicine is wasteful, the incidence of injury would be no greater, only the incidence of liability-assuming that defensive medicine really protects against successful claims.) Conversely, if plan doctors maintain a defensive practice style, they will lose financially. In contrast, traditional insurance arrangements cannot reward doctors for ordering fewer tests or

16. Accord Law, A Consumer Perspective on Medical Malpractice, Law \& Contemp. Probs., Spring 1986 , at $305,308-09$.

17. In practice, how an HMO, PPO, or other entity achieves its goals varies tremendously: Methods of payment for providers, as well as other controls, must be tailored for each situation. The key point is that the delivery organization can redesign incentives and redirect resources. 
performing fewer services and so cannot deter defensive medicine in the same way.

Conventional malpractice reform cannot save nearly as much as alternative delivery systems. Even in the most optimistic conventional reform scenario, premiums will not fall to zero, so savings must be less than current malpractice costs. In contrast, the costs of defensive medicine that alternative delivery systems can-and conventional insurance cannot-save can be several times as large.

The second advantage of alternative delivery systems is that they naturally and almost automatically attack what is the major source of malpractice costs according to one common theory. This theory, which the AMA's board of trustees seems to endorse, ${ }^{18}$ maintains that there are very few really bad doctors in practice and that they are largely responsible for the problem. Alternative delivery systems select the providers they accept into their systems and have a powerful incentive to weed out the worst practitioners to the extent that such practitioners can be identified. As a result, the malpractice experience of alternative delivery systems should reflect the gains available from getting rid of the "bad apples."

The third advantage of alternative delivery systems is the improved oversight of medical practice they create. In the conventional, insured, feefor-service world, no one watches closely what providers do. In alternative delivery systems, there is substantial collegiality and peer review-directed both at utilization management and at quality assurance. ${ }^{19} \mathrm{~A}$ major reduction in deficient practice and in mistakes should, in theory, follow. Even if, in practice, oversight in alternative delivery systems may not be as extensive as it ideally should be, it is far more extensive than in the fee-for-service system.

Fourth, alternative delivery systems can easily attack another leading cause of malpractice claims according to another reigning theory, also espoused in AMA documents. ${ }^{20}$ This theory holds that malpractice claims have little or nothing to do with the technical quality of care. Rather, it asserts, claims fall almost at random, like bolts from the blue, upon good physicians as well as poor, when physician/patient communication breaks down. Some data support this theory by showing that relatively few of the total number of malpractice suits are brought against "repeat offenders." 21 According to this theory-inconsistent though it may be with the opposite hypothesis also maintained by the AMA - the bad deeds of the bad apples do not contribute much to the total picture.

An alternative delivery system can readily work in an organized fashion to prevent communication breakdown and head off communication failures that cause malpractice problems. Many alternative delivery systems have patient

18. See Brinkley, supra note 7 .

19. For a theoretical review of these quality incentives in the HMO context, see Bovbjerg, The Medical Malpractice Standard of Care: HMO's and Customary Practice, 1975 Duke L.J. 1375.

20. AMA TASK ForCE, RePORT 2, supra note 11, at 8, 10.

21. Id. at 10 . 
advocates or ombudsmen whose prompt intervention-carrying patients' complaints to physicians-may well help avoid communication failures, growing patient anger, and resulting lawsuits. The same advocates could easily function from the other end of the communication channel, teaching physicians "risk management"- that is, how to communicate better with patients to improve care, increase satisfaction, and reduce the potential of a malpractice claim when an injury occurs. And, to close the loop, patients need to be educated about what expectations are realistic. This process, too, is more easily implemented in an organized system of care. Although risk management and education programs, unlike the first three advantages mentioned, are not an almost automatic feature of alternative delivery systems, they are more readily pursued in an organized system.

Fifth, alternative delivery systems can serve as group purchasers of malpractice coverage for their individual practitioners. If, as is argued above, their experience is indeed more favorable than average, they can seek and probably obtain favorable terms from insurers as a group with favorable experience. Alternatively, if they are large enough, they can self-insure, thus directly capturing the benefits of their own presumably good performance. Finally, a group of alternative systems might try forming their own malpractice insurance company, much as medical societies did under the AMA's aegis a decade ago. ${ }^{22}$ This mutual insurance approach offers a way to make the fruits of favorable experience available to smaller alternative delivery systems.

At this point, a note of caution is in order. Except for a few large HMO's (most notably Kaiser), alternative delivery systems today use the same malpractice insurers and pay the same rates as conventionally insured, fee-forservice providers-although many hospitals do self-insure. Data on the malpractice claims experience of alternative delivery systems are not available, so that the real extent of their apparent advantages in malpractice costs is not known. Given the widely variant theories on what causes malpractice claims, one should be a bit cautious in making a priori judgments. ${ }^{23}$ But recall again that malpractice premium costs are only a small fraction of health care costs. In terms of total health costs-in which malpractice premiums and even defensive medicine are only a modest fraction of the total-it is wellestablished that alternative delivery systems, or at least HMO's, achieve major savings. ${ }^{24}$ Increasing competitive pressures might well induce further savings on the malpractice front.

22. See Posner, Trends in Medical Malpractice Insurance, 1970-1985, LAw \& Contemp. ProBs., Spring 1986, at 37, 43-44.

23. In 1985 in Michigan, contrary to usual practice, a physician-owned mutual attempted to institute higher premiums for doctors in an alternative system, admittedly without evidence of worse malpractice experience. Michigan MDs in HMO's, PPO's Face Higher Liability Premiums, AM. MEd. NEws, July 12, 1985, at 1 .

24. Manning, Leibowitz, Goldberg, Rogers \& Newhouse, A Controlled Trial of the Effects of Prepaid Group Practice on Use of Services, 310 NEW ENG. J. MED. 1505, 1507 (1984). 


\section{The Potential for Innovations in Malpractice Arrangements in Alternative Delivery Systems}

The malpractice reform initiative that alternative delivery systems are most likely to take in the near future is the development of a "better mousetrap" for handling malpractice claims. The easiest and most acceptable innovation would be a simple agreement by those who enroll in alternative delivery systems that their initial recourse in pursuing malpractice claims will be to mediation and arbitration. Mediation and arbitration could be made compulsory, but results need not be binding. That is, enrollees would not have to surrender their right to take their case to court if an arbitration award is not acceptable.

Such an arrangement would meet the second and third requisites of a successful solution by getting more of the premium dollar to injured patients more quickly without waiting for a solution to the problem via statutory reform. Moreover, it offers enormous advantages of practicality and attainability compared with other reform proposals. By not attempting to change basic tort rights, this proposal would not encounter resistance from union leaders and employee benefit managers, who are hesitant to introduce changes that may be disturbing to the rank and file. The proposal would be consistent with what seems to be the public's sentiment against basic changes in available recourse to the court system. ${ }^{25}$ Finally, unions are very familiar with arrangements of this kind, in which mediation and arbitration of unresolved issues are preliminary steps and stronger action is available later. Contract negotiations commonly go to mediation, for instance, without foreclosing the ultimate weapon-the right to strike.

Unions are coming to recognize the promise of alternative delivery systems as a means of stretching benefits at a time when funds are tight and health costs are climbing rapidly out of sight. Introducing mediation and arbitration in the positive context of alternative delivery systems-a context in which payers and patients are clearly sharing in savings-will be much more acceptable than introducing it in the conventional fee-for-service context. Success with nonbinding arbitration in alternative delivery systems might pave the way for its more extensive adoption subsequently. For example, if experience shows that it produces good results in alternative delivery systems, receptivity to legislation requiring it might increase, or union and management officials might welcome it in fee-for-service health plans. Moreover, the future may see new direct arrangements under which unions contract directly with providers-omitting insurers, HMO's, or other intermediaries. The incorporation of nonbinding arbitration in such direct arrangements would follow logically and bring the benefits of this "better mousetrap" to a wider group of employees.

25. See supra note 14. 
Adoption of more extensive changes in malpractice procedures and rules is likely to require extensive education and to be a slow process, if it ever comes about. ${ }^{26}$ The demonstration that one change-the use of compulsory but nonbinding mediation and arbitration-has beneficial results is likely to be a telling argument in this educational process and to increase the acceptability to interested parties of further change. Such further change might include modification of tort-law rules through private contract, as advocated by Clark Havighurst elsewhere in this symposium. ${ }^{27}$ In this case, management and union leaders will be the primary parties to be educated. Alternatively, further change might come about through legislation, in which case the educational process will have to reach a much broader audience.

26. On this point see Havighurst, Private Reform of Tort-Law Dogma: Market Opportunities and Legal Obstacles, Law \& Contemp. Probs., Spring 1986, at $171 \mathrm{n} .91$.

27. See generally id. at 157. 